\title{
Seeing into Ubiquity
}

\section{Danae Stratou}

\section{Introduction}

The Lascaux Cave Paintings in France are the earliest known images ever created by man. Since its discovery, cave art has provoked great curiosity about why it appeared, when and where it did, how it was made and what it meant to the communities that created it. David Lewis-Williams proposes that the explanation for this lies in the evolution of the human mind. ${ }^{1}$ Cro-Magnons, unlike the Neanderthals, possessed a more advanced neurological makeup that enabled them to experience shamanistic trances and vivid mental imagery. It became important for people to 'fix', or paint, these images on cave walls, which they perceived as the membrane between their world and the spirit world from which the visions came. The notion that the first images ever made were actually expressing the need to capture 'internal' visions and bring them out, to make them visible to the 'external' world, seems to me an intriguing idea.

\section{Point of departure | Initial process}

I imagine two parallel realities in the way that we view the world. There is the world inside and the world outside us. It is through the senses that we are able to connect the inside to the outside world. My whole life, including the choice to become an artist, has been an attempt to re-search, to understand, and to connect these two parallel realities. To bridge what is within to what is without.

Naturally my works are triggered by or have a point of departure either in the external or in the internal world. Initially, an idea is generated in the form of an internal image, which in turn needs to be answered intellectually and put into context. This process seems to me to have its point 
of departure in the world of the subconscious, which then surfaces into the conscious realm. Following from there, the initial idea decodes itself as it evolves into realisation and ends up 'translating itself' into an artwork. It is a bit like a journey, which slowly reveals itself as I journey along.

The reason most of my work takes the form of tactile, multimedia installations lies in my aim to involve the viewer in a physical way; to enable her or him to become immersed into it. In order to achieve this physical 'pull' I often use rhythm and repetitive movement. They reflect the pulse and recurrence that are constitutive of life. They are basic elements of life itself. Rhythm and repetition help open up and prepare the mind for the elusive connection of the conscious and subconscious worlds.

\section{Work process | Realisation | Techniques}

If we accept, as is my view, that there are two simultaneous, two parallel realities where one is within and the other external to us, then we can make the hypothesis that there are also two kinds of images. There are the images generated inside our heads, such as dreams and visions that are woven from the stuff of our conscious or unconscious imagination. Then there must be the images that reflect-however imperfectly - the external world, which we conceive as it appears to us through all of our senses. What we see, touch, hear, smell is then processed in different parts of our brain and as a result becomes the holistic experience of the world as we-each individualperceives it. Part of this experiential process, especially if one is a visual artist, is to connect the ubiquity of the images inside to that of the outside world. This was a critical feature of the photographic sequence and the juxtaposition of a wall text written by my collaborator Yanis Varoufakis for our work The Globalising Wall. (Figures 18 \& 19) In the exhibition 'Restless' (2012) we included the following statement:

CYPRUS: GREEN LINE | KOSOVO: NORTH-SOUTH MITROVICA | N. IRELAND: BELFAST | WEST BANK: PALESTINE | MEXICO-USA: BORDER FENCE 


\section{DANAE STRATOU: SEEING INTO UBIQUITY}

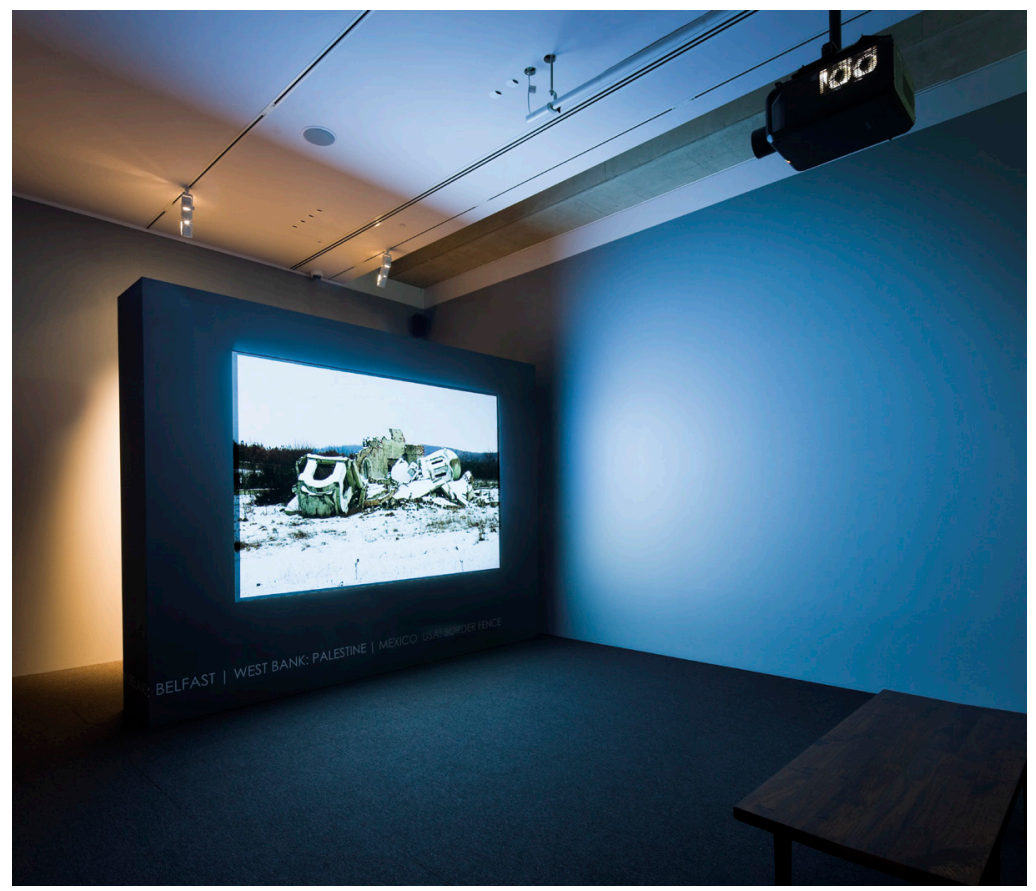

18 Danae Stratou and Yanis Varoufakis

The Globalising Wall, 2011 

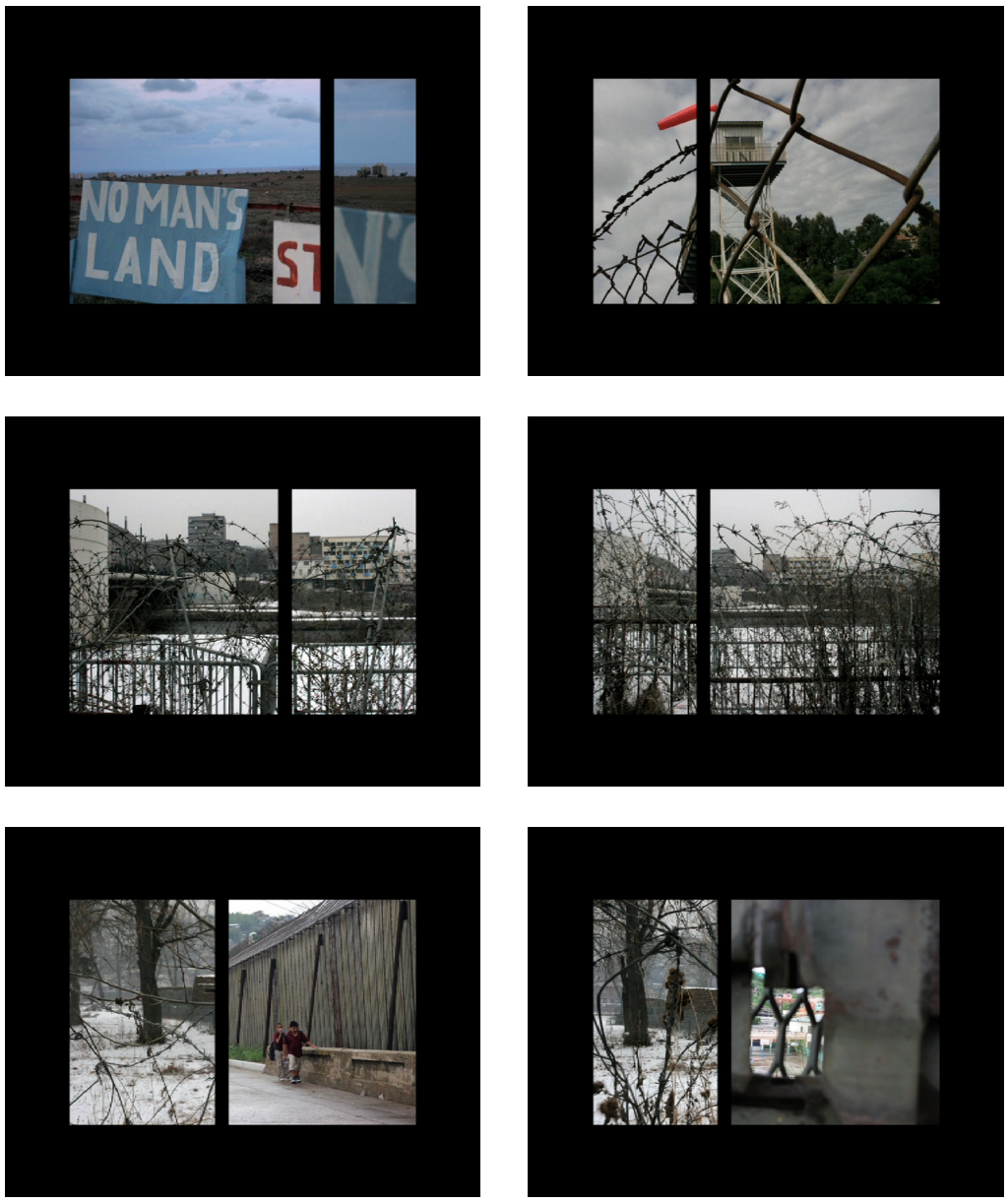

19 Danae Stratou and Yanis Varoufakis The Globalising Wall, 2011 
Walls have a longstanding relation both with liberty from fear and subjugation to another's will. After 1945, walls acquired an unprecedented determination to divide. They spread like a bushfire from Berlin to Palestine, from the tablelands of Kashmir to the villages of Cyprus, from the Korean peninsula to the streets of Belfast. When the Cold War ended, we were told to expect their dismantling. Instead, they are growing taller, more impenetrable, longer. They leap from one continent onto the next. They are globalising. From the West Bank to Kosovo, from the gated communities of Egypt to those of California, from the killing fields of old Ethiopia to the US-Mexico borders, a seamless wall is meandering its way, both physically and emotionally, on the planet's surface. Its spectre is upon us.

As I mentioned above, all my work is triggered or has a point of departure either in the external or in the internal world. Initially, an idea or an internal image is generated, which in turn needs to be answered intellectually and put into context. This intellectual process is necessary to give form to (what seems like) an inspirational idea. This procedure is not that simple, of course. It takes time for all the pieces to come together, until they can reach a final form. In the same way I imagine scientists, or mathematicians, may initially visualise a formula they instinctively believe to be true, but must then go through the elaborate process of proving it to be true. In our case, the artwork combines both the formula and the proof.

This journey hopefully results into two different kinds of works for me: the ones in which I create or construct an environment or an installation without the use of any sort of a depicted or 'external' image and then the works in which I use photography or video.

In the case of creating or 'constructing' an installation without the use of video or photography, things are quite straightforward. As the process of intellectualising an idea concludes and takes form, I first envision what it is that I want to create and I then start to work out the best way in which I will be able to realise it. At that point, as the phase of materialisation begins, I come face to face with constraints, such as natural and physical restrictions posed by the laws of nature, 
material limitations, time constraints, budget limitations and so on.

At each step of the way these constraints raise questions that demand me to make choices. It is through these choices that the work takes its final form. This process is, in my opinion, crucial since it helps clarify even further and deeper the essence of the initial idea, thus helping me get rid of any non-essential elements and get even closer to the core.

In the case of the works in which I use external images, plundering with my camera the ubiquity of images around, there is a significant difference in the approach and procedure. Ever since I started working as an artist, I decided not to set up or direct the images that end up comprising my photographic and video works. On the contrary, I have made the choice to use images that I shoot as they unfold in the real world; real life moments, that is. As a result of this choice I have accepted and embraced the idea that random elements are largely a part of the quality and character of these works. There is a lot that cannot be controlled in this process. Of course this entails the risk of not 'finding' what I am looking for, as well as the risk of ending up with too little or too much footage. What I do in order to minimise these risks is that, before I embark on such a project, I have a very clear and focused idea of what it is I am aiming at. I choose my parameters and impose my own constraints on what images I want to capture. (This is similar to the other exogenous constraints that I mentioned above as well as to the restrictions that also occur in other types of project). Then, when I return to the multitude of imagery, it is as if the images I select for use (either as stills or footage for incorporation into a video work) 'present themselves', rising inconspicuously from the ubiquity, from the abundant digital material, and find their own place in the final selection, hopefully telling the story I had embarked out to tell in the first place.

Another issue that comes up in all of my work, independently of whether it is a video work or an installation project, is my effort to involve the viewer in a physical way, to enable her or him to become emerged into it. To achieve this physicality in the video/photographic works, I actually need physically to situate myself and my camera in a specific location or 
condition so that it will be in the position to capture the image or portray the impact-movement, or sensation - that I am aiming for. It becomes physical through the action itself at the moment of shooting.

I have already mentioned that, to pull the viewer into the work, I often rely on rhythm and repetitive movement. Both these qualities are a basic element of life itself, as in breathing for example. Rhythm and repetition helps the mind open up to an almost 'meditational' state so that a connection of the conscious and subconscious worlds can be enabled.

\section{Notes}

1 D. Lewis-Williams, The Mind in the Cave: Consciousness and the Origins of Art (London: Thames \& Hudson, 2002). 